\title{
APPLICATION OF ROBOTIC SYSTEM FOR OBTAINING INFORMATION ABOUT THE AREA
}

\author{
A.P. Makarov*, A.G. Chibunichev, E.V. Poliakova \\ Moscow State University of geodesy and cartography (MIIGAiK), 4 , Gorokhovsky pereulok, Moscow, RUSSIA, \\ mapdir@yandex.ru, agchib@mail.ru, ekat.polykova@yandex.ru
}

\section{Commission II}

KEY WORDS: Automation of aerial photography, UAV, robotic system, navigation, charging station

\begin{abstract}
:
The Photogrammetry Department of MIIGAIK is developing the "Automated Information Generation System" (AIGS), which is designed to carry out automatic aerial survey of the object using a drone and obtain documents about the terrain (orthophotos, DMR, etc.). The system is based on a robotic mobile platform with a navigation system installed on it, a manipulator and a lifting portal. The manipulator has three degrees of freedom and is designed to manipulate the necessary when replacing automatically the battery in the UAV. The lifting portal is designed to load and fix UAVs on the platform. The robotic station is able to work both individually and as part of a network of stations. Complexes are evenly distributed on the territory where aerial photography or monitoring will be carried out. The operator is in the office, forms the job and sends it over the Internet channel, at the station. The job is run automatically on schedule
\end{abstract}

\section{INTRODUCTION}

Recently there has been a very rapid growth of the UAVs introduction, in all areas of human life activities. Until recently, about 10-15 years ago, independently flying, the aircraft seemed from the field of fantastic films. And today even a child can become the owner of such a device. Moreover, he will be able to manage it confidently. Flight itself, of course, the spectacle is magnificent, but such an aircraft equipped with a video camera, become a very useful tool in everyday life. Now it has become possible with the help of such a device, to look into the most impassable, the most hidden previously from the eyes of man, places. And this is not just for the sake of simple curiosity. Vitally, the use of such devices to search for missing people during bad time, in the forest, in the mountains after avalanches. To consider and determine the direction and speed of the spread of oil spill, chemicals. Monitoring, rapidly changing conditions during fires, floods and other emergencies. The use of UAVs in the cadastral and mapping industries is very good. With the use of UAVs in these areas, the cost of finished products is steadily decreasing and the speed of obtaining mapping products is increasing. But, despite the enormous benefits of using this technology to obtain information about the territory, there are a number of problems that make these benefits sometimes negligible. The main problem here is the lack of qualified specialists in the field of aerial photography. The problem arose because of the lag of training from the technical development of the industry. According to our expert observations, the situation has developed in such a way that $90 \%$ of aerial surveys unfulfilled or completed, but with a marriage, occur due to the weak skills of specialists. The problem is also the huge number of factors that need to be considered when preparing for a autonomous flight. If earlier at least 5 specialists (pilot, navigator, flight operator, headband, meteorologist, driver, etc.) participated in the preparation of the aerial photography flight, now all the knowledge of these specialists should have 1 person. The pilot himself must have certain psychological qualities. It should be resistant to various stresses, reasonable and have a good reaction, which is not always present in professionals who have decided to take up the profession.

\footnotetext{
* Corresponding author
}

Having a great experience of aerial photography since 1980, and having analyzed the trends taking place in the world, due to the penetration of this technology into the life of mankind, we came to the conclusion that for a favorable entry of UAVs into the production field, it is necessary to supplement the available capabilities, automation full-time cycle of information, from the project to the receipt of finished products. Then it is possible to solve most of the problems described above, and the use of such technology will bring for inexpensive cost, safety, convenience and speed of requested information. Especially with all the components of this automation, for this solution already exist. There is software for design, UAV flying on projected routes is there, there is software for processing the data. There is a small gap that connects all these processes together and automates UAV services. How does this happen today? We receive an order to perform the aerial photography. We carry out preparatory work, determine the location of the site, prepare the project, prepare the equipment, load the equipment into the transport, transport the equipment to the site of the aerial photography, make reconnaissance of the area, determine the point of take-off/landing, prepare UAVs. The pilot gives command for take-off, controls the flight, makes a landing. After landing, the UAV pulls out an SD card, downloads information on the PC. Forms a block to process images. Launches software for includes software for photogrammetric processing. Forms output products. Gives the customer the completed task. And these processes are repeated every time an order arrives. With this approach, often the same territory is removed, in the same period for many times, by different customers. Every time there are logistical costs for the delivery of UAVs, equipment, specialists to the location of aerial photography. Every time you need a professional pilot. The accuracy of the material varies from survey to survey. This type of logistics results in a very low speed of obtaining primary data.

\section{DESCRIPTION OF AUTOMATED INFORMATION GENERATION SYSTEM}

The main idea is as follows. In the territory to be monitored, evenly have so-called points of information generation 
(executive complexes). All complexes are connected in a common network and are controlled by software installed on servers. Each server is responsible for a specific area with executive complexes located on it. All servers are connected by Cloud Technology. Users, through such a service order interesting information to a certain territory, and the system determines the executive complexes that will be able to perform the task. Then the task is transferred to the selected complexes, which independently begin to perform the task. The information is then automatically transmitted over the radio channel to the server. If additional processing is required, it is performed and then sent to the customer. With such organization of aerial photography there is no need for logistical costs, work on the conduct of flights will be more safe, as flights are designed and performed by an automated system without specific human factors. Permits also formalize this system. If the job is similar to the one recently completed, the system will offer to use the finished product with a significant reduction in cost. There is no need to look for a qualified pilot, to maintain technical equipment for the aerial photography and its maintenance specialist. The time to obtain primary data is reduced to a few tens of minutes. The use of such a system will increase the number of customers, due to the availability and convenience of ordering obtaining the required information. Naturally, the more established data generation points, the more service area and the more customers. It must be said that the service area of one complex, which includes one Phantom 4 RTK-type UAV, covers the territory for service of at least $200 \mathrm{sq} \mathrm{km}$. The flight time from the take-off point in the center to the furthest point of interest is less than 6 minutes. Such a system has the following block structure. Key blocks of the Automated Information Generation System:

1. The block of receiving, forming and issuing an order.

2. Permit preparation block.

3. The Block of choice and preparation of the Executive Complex.

4. Robotic Executive Complex Block.

5. Processing block.

Figure 1 shows the structure of the Automated Information Generation System (AIGS)
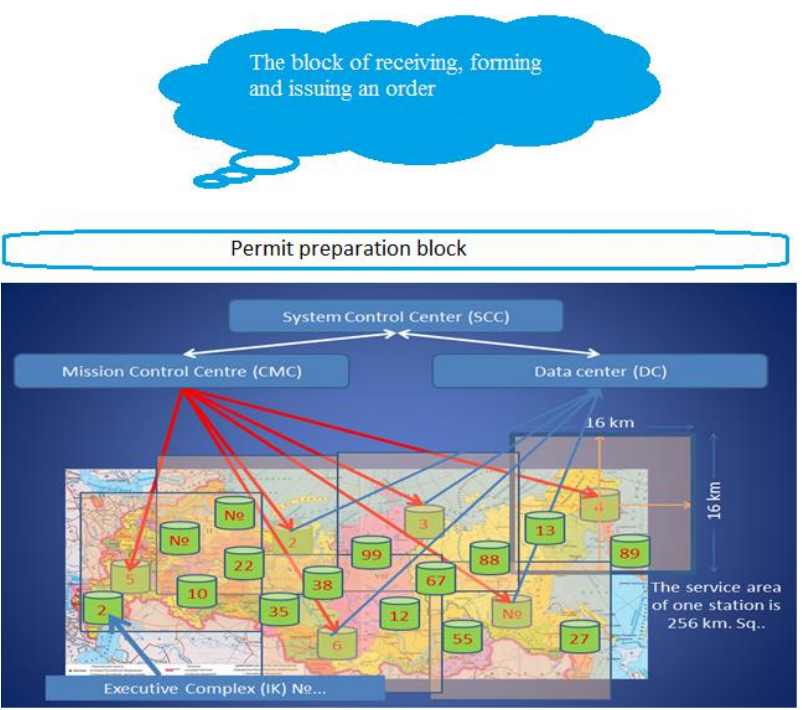

Figure 1. Structure of the AIGS system
Let's take a closer look at the most complex, but also the most interesting block - Robotic Executive Complex. The complex consists of 3 main modules: Robotic mobile platform, Aircraft, Charging station. Such a complex can be supplemented by a closed hangar, in which can be another 2 aircraft, 10-20 batteries for aircraft and a weather station. The complex can simultaneously control 3 aircraft.

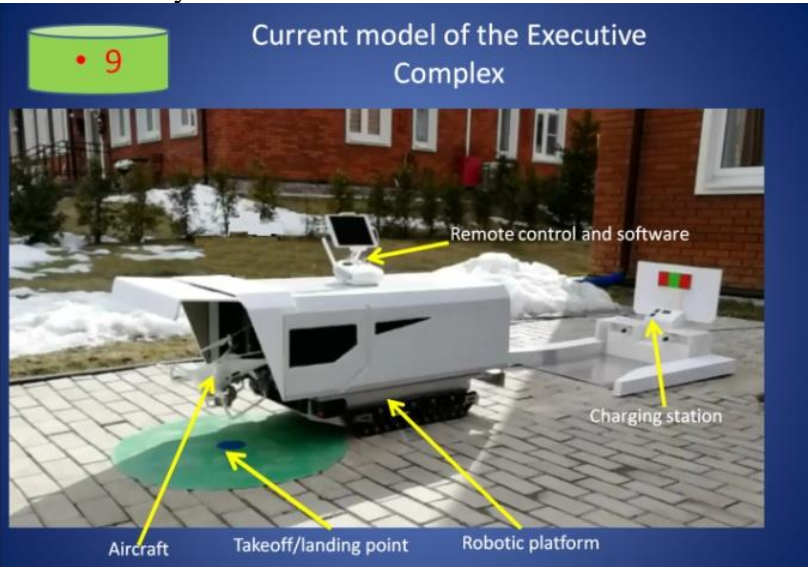

Figure 2. Appearance of the Executive Complex

1. On the Internet radio channels in the tablet receives a flight mission. With the help of a special program, the task is processed into the internal instruction of the complex, information is collected from various sensors, the technical ability to complete the task is determined (flight range, availability of charged battery, weather conditions, etc.). If all parameter are normal, the complex sends a report on the state of preparation for departure to the server. If everything is normal, the server allows the flight.

2. At the scheduled time, the robotic platform travels along a pre-specified route to the point of take-off/landing. While driving, using a stereo camera, the mobile platform circles the obstacles that arise in the way. After reaching the final destination, using a specially designed manipulator, it turns on the aircraft, located inside the platform. The manipulator is developed on the basis of well-known principles of robotics [Badgers, A.P., 2010, Preco M., 2007]. Then checks for remote control connection with UAVs. Determines the capacity of the SD card, if it is sufficient, put the UAV on the point of takeoff/landing. Moves 2-3 meters back, freeing up space for takeoff.

3. The flight mission is loaded into the UAV. The command to take off is given.

4. During the flight mission, the complex constantly monitors the location of the UAV according to the given route. Controls the remaining capacity of the UAV battery and, when you reduce the preset, remembers the point of continuation of the job and gives the command to return the UAV to the landing point.

5. When the UAV arrives at the landing point, the device begins to drop to a height of 18 meters. Then the UAV turns in the direction that was at takeoff, turn the camera into the nadir and begins to search for the point of takeoff/landing. A special label is used for this purpose. The device is lowered while adjusting its position. As soon as the landing happens, the engines are turned off.

6. After stopping the engines, the mobile platform start searching for UAVs. The platform, using a stereo camera located in the front part, determines the direction and distance to the aircraft by color labels. Gently drives up to the UAV at a distance of $30 \mathrm{~cm}$, corrects its position relative to the UAV, 
lowers a special portal with captures, gently presses them to the chassis of the UAV and takes over, then lifts to the platform and fixes the UAV on the platform. After that, the manipulator disconnects the aircraft and uses a special manipulator to replace the battery in the UAV.

7. If the job is not completed, the manipulator takes the battery out of the UAV, inserts it into the charging cell, takes out a charged battery from another cell, and inserts it into the UAV. Then the actions are repeated in a cycle, starting from point \#2

\begin{tabular}{|c|c|c|}
\hline $\begin{array}{l}\text { № } \\
\text { ПI/ா }\end{array}$ & Characteristic & Value \\
\hline 1 & Service area & 16x16 km.(256 sq.km.) \\
\hline 2 & Temperature & $-10^{\circ}+40^{\circ}$ \\
\hline 3 & Power station voltage & $220 \mathrm{v}$ \\
\hline 4 & $\begin{array}{l}\text { Base station power } \\
\text { supply }\end{array}$ & 22v 6s Lipo48000 \\
\hline 5 & $\begin{array}{l}\text { Station time without } \\
\text { recharging }\end{array}$ & 8 hours \\
\hline 6 & Copter battery time & 1.5 hours \\
\hline 7 & $\begin{array}{l}\text { Number of batteries on } \\
\text { the mobile platform }\end{array}$ & 5 \\
\hline 8 & $\begin{array}{l}\text { Time to replace copter } \\
\text { batteries }\end{array}$ & $2 \mathrm{~min}$. \\
\hline 9 & Maximum wind speed & 10 meters per second \\
\hline 11 & Storage device & SD \\
\hline 12 & Robot control & Bluetooth or Wifi \\
\hline 14 & $\begin{array}{l}\text { Size/weight } \\
\text { power items) }\end{array}$ & $\begin{array}{c}9000 \times 600 \times 550 \mathrm{~mm} \\
20-25 \mathrm{~kg}\end{array}$ \\
\hline
\end{tabular}

Table 1 The specifications of the complex

This layout requires about 10 square meters of flat ground. The complex can be located under a canopy protecting from direct precipitation, sun and dust. The charging station must be supplied with a constant power supply of 220 volts or an autonomous power source obtained using a gasoline generator. The mobile, tracked platform runs from a battery of $22 \mathrm{v} .48,000$ $\mathrm{a} / \mathrm{h}$ and can travel autonomously for up to $1 \mathrm{~km}$. With 5 charged batteries for UAVs on board, the platform can provide autonomously up to 8 departures using only its power battery. At the same time, the duration of pure flight time can reach 240 minutes. After that, the platform will arrive at the charging station on its own, using a stereo camera, and will recharge its battery. Several modifications of such complexes, varying functionality (Figure 3,4) have been developed.

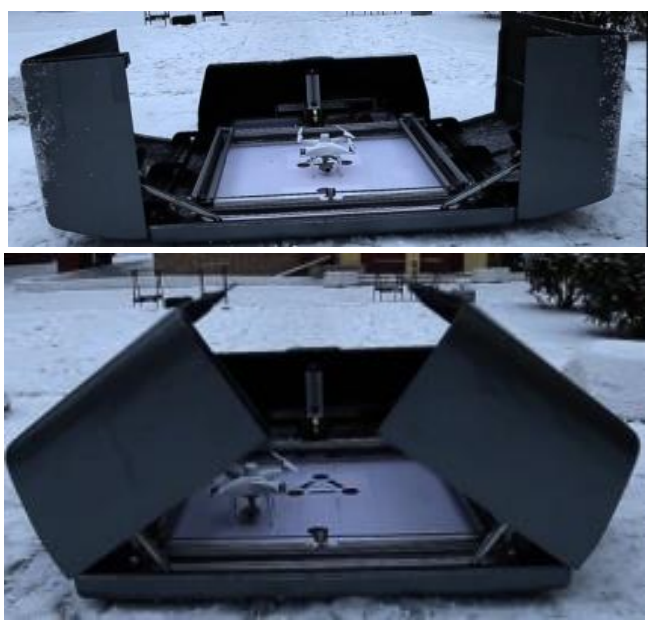

Figure 3. Stationary complex - Installed on a car trailer, trunk. The UAV lands in the box.

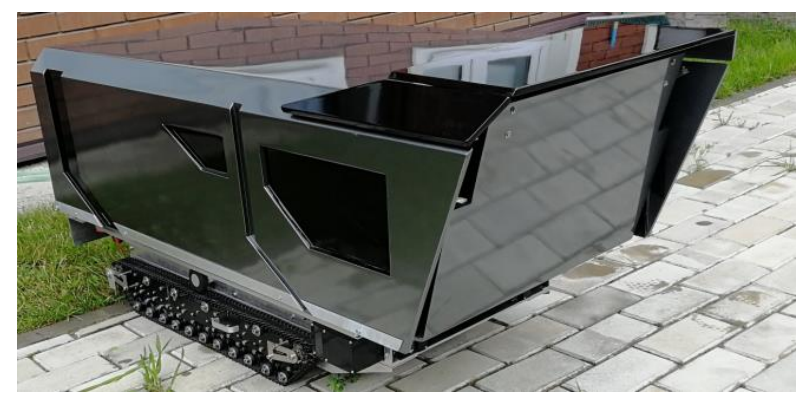

Figure 4. Mobile complex on tracked course - radius of autonomy $1000 \mathrm{~m}$. speed $5 \mathrm{~km} / \mathrm{h}$. UAV lands on the ground

Today, many teams in different countries are engaged in such developments. Figures 5-11 show the main UAV stations for battery charging.

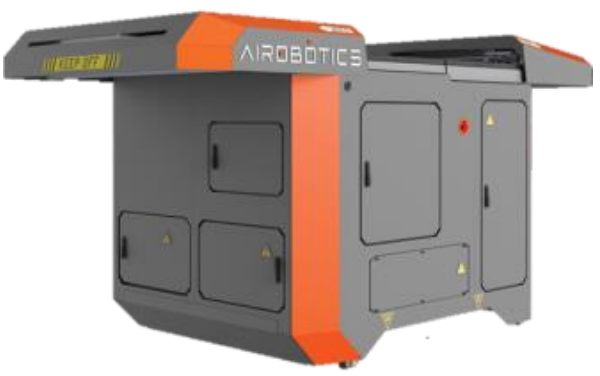

Figure 5. Airobotics Drone Base (Israel)

https://www.airoboticsdrones.com/ Last Accessed: March 2020

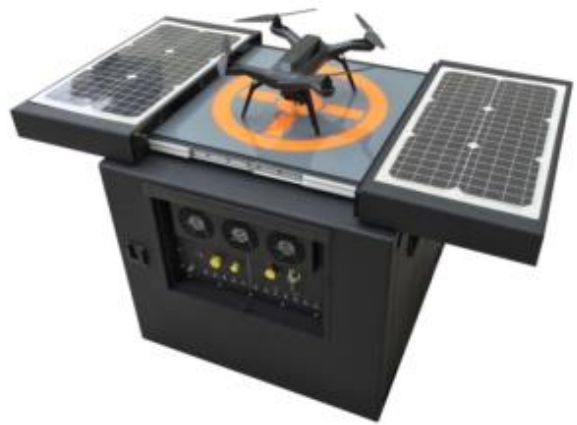

Figure 6. Skysence USA Charging Station (http://www.skysense.co/charging-pad-indoor/ Last Accessed: March 2020)

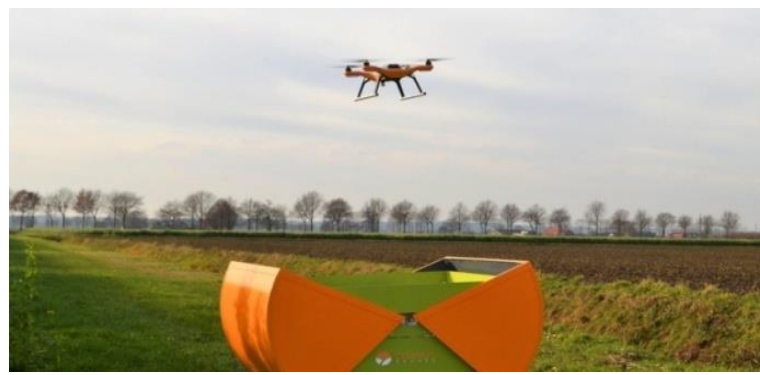

Figure 7. CorvusDrones charging station (Netherlands) https://www.corvusdrones.com Last Accessed: March 2020 


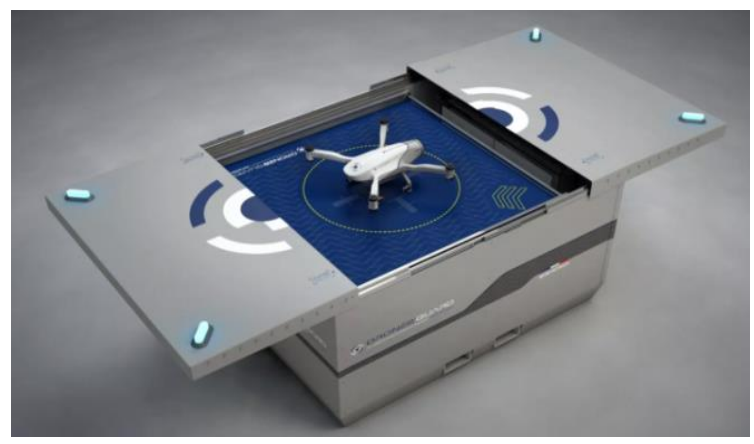

Figure 8. AzurDrones charging station (France) https://azurdrones.com/en/ Last Accessed: March 2020

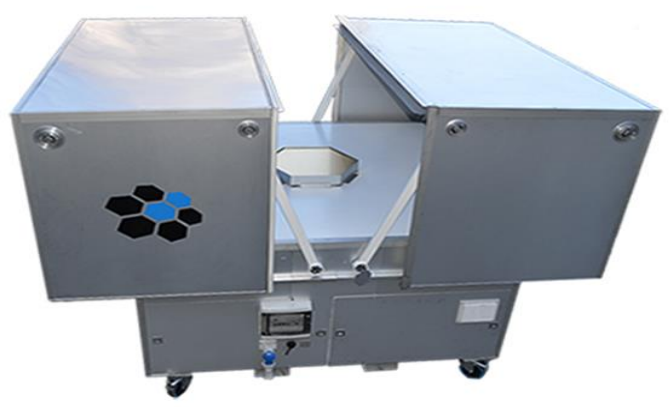

Figure 9. DroneBox Station (Singapore) http://www.h3dynamics.com/products/drone-box/ Last Accessed: March 2020

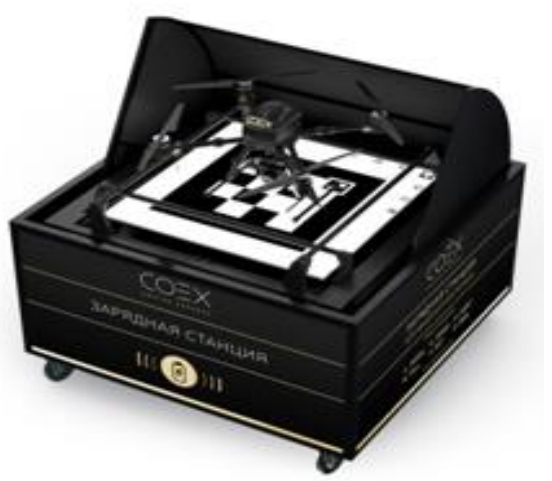

Figure 10. Copter Express Charging Station (Russia) https://copterexpress.ru/pelican. Last Accessed: March 2020

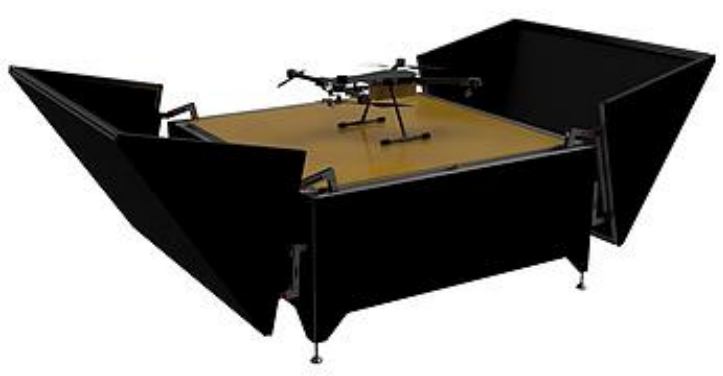

Figure 11. «RoboFlot» Charging Station_(Russia) https://www.roboflot.ru/autonomous-copter Last Accessed: March 2020
All of the above developments have in their complex a specialized UAV, designed only for this complex. Everywhere the UAV lands directly on the site located in the receiving station. Many complexes only have battery charging. All these factors greatly reduce the potential for the use of these complexes. The development presented is devoid of these limitations. The system initially knows how to service various UAVs and devices. That is, this complex can be trained to change not only batteries, but also the payload, the capacity of agricultural chemicals, aircraft, etc. Complex can perform more than 100 separate commands. Such, for example, how to turn the platform to a given angle, raise the manipulator with capture to a certain height, measure the distance to the UAV, drive directly specified distance, with accuracy of $1 \mathrm{~cm}$, etc. By combining such commands into text scripting files and assigning them an index number, the user can program the complex to perform their tasks. The system has a learning mode. By enabling learning mode, the user, with the help of manual commands, once produces maintenance of UAVs (lifting/descent of UAVs to the platform, replacing the battery, etc.). The system remembers the necessary service parameters, assigns the identification number for this UAV and records them in a file on the SD drive. Thus, the system can independently (without developers) to expand the types and brands of UAVs, which in the future will be able to serve. Naturally, the UAV must correspond to the dimensions and weight, parameters of the complex.

In addition, one of the significant differences from the above developments is the possibility of landing aircraft NOT exactly in the designated place, but within a radius of 10-15 meters to the ground. This is safer for UAVs because the accuracy of landing is strongly affected by weather conditions (wind, rain, snow, dust, dirt, external interference). If the UAV for any reason touches the structure of the complex, the consequences can be fatal for the UAV and the performance of the mission as a whole. In our system, the UAV can land in a designated location with the accuracy of its navigation system. The mobile platform will still detect it with a video camera, drive up and load it to its platform, serve, as stated in the task. Also, if there is an unsuccessful landing (overturning UAVs, but not more than $50 \mathrm{~m}$ ) the robotic platform is able to track down UAVs, load and deliver to the destination. The mobile platform can serve multiple UAVs at the same time. Running and taking $\mathrm{UAVs}$ at short intervals. And control of the flight mission is conducted separately for each UAV. In other words, aircrafts can simultaneously perform completely different types of tasks. For example: one to conduct observations in order to protect the perimeter, the second to perform a square aerial survey, the third to shoot circular 3D panoramas. This reduces the total time of the job several times or allows monitoring of the event 24 hours a day, starting the UAV to replace the previous one, when the first begins to run out of electricity.

One advantage of this complex is its ability to position in office space. That is, it does not have to have a separate hangar. It is only necessary to ensure an unhindered exit of the platform to the takeoff point of the UAV. For example, by placing a charging station in the office, which has an open terrace, it is possible to indicate a mobile platform, a way to go to this terrace, where you need to place the point of take-off/landing. Now the complex will be able to travel to the point of takeoff/landing, run and meet UAVs and at the same time be under surveillance, protection, protected from adverse weather conditions and fully ready to perform the tasks. If there is no terrace it is possible to use flat roofs. The complex is built on the principle of open architecture and can be built into various automated systems, as it has on board a customer processing 
server, a stack of tasks, its calendar, watch, weather station, solid state storage for 1TB. Communication with the complex takes place on Radio channels WiFi. Up to 3 users can connect to the complex at the same time. Everyone has their own virtual space to interact with their UAVs. There is a job editor, can work both autonomously and as part of a network of such complexes. As a result, we will list the differences and advantages of this complex from competitive developments.

1. Can learn to service different devices.

2. Maintenance of serial UAVs of various manufacturers and different brands.

3. Can service multiple UAVs at the same time

4. The possibility of a UAV landing on the ground within a radius of 10-15 $\mathrm{m}$ from the point of take-off.

5. In the case of the fall of the UAV, the complex can search and evacuate the UAV.

6. Can work from enclosed spaces.

7. There is a charge and replacement of UAV batteries

One of the main differences of this complex is its mobility. Currently, there are quite a lot of different real mobile robotic systems, created mainly for automatic indoor photography (Bazhan, S., et al., 2019, Mustafa K. A. A., et al., 2019, Wu, W., et al., 2019, Calero, D., et al., 2017, Chen, C., et al., 2017, Calisi, D., et al., 2017, Borrmann, D., et al., 2015) or outside (Wu, W., et al., 2019, Calisi, D., et al., 2017). These robots use different platforms on 3,4 and 6 wheels or tracks. For autonomous orientation, they use a variety of equipment: IMU, odometers, scanners, Kinect, video cameras, panoramic cameras, stereo cameras, etc. Most developments are focused on the use of low-cost equipment (Calero, D., et al., 2017, Chen, C., et al., $2017 \mathrm{Wu}, \mathrm{W}$., et al., 2019). It's natural. We are also focused on low-cost navigation equipment. It consists of a geodesic class of GNSS GPS receivers, a front stereo video camera, allowing you to build a model of obstacles in real time and a video odometer, developed on the basis of the video camera OpenMV. Stereo cameras work under their own software (Chibunichev A.G. et al, 2019), based on the micro computer "StereoPi". The software is based on well-known image processing algorithms and computer vision (Kostrov, B.V., 2008, Preco, M. 2007). The front stereo camera is trained to recognize the color tags located on the path of the mobile platform. These tags define the path of movement of the mobile platform. With these tags, you can specify the platform, perform certain actions, such as stop, turn, lower UAVs, drive through the doorway, etc. In this way, the platform is navigated inside the premises by color codes. It is also possible to specify to the navigation system how much and in which direction to drive from the initial position of the platform, and the video odometer will monitor its movement with $1 \mathrm{~cm}$ accuracy.

While moving in real time, the program, according to the video stream stereo camera, builds a points cloud. Further from this cloud are built so-called isolations of obstacles, which eventually form the basis of decisions on the choice of direction or unhindered movement forward. The entire trajectory is recorded on the SD storage and can be used for further location analysis as well as back-to-back. Thus, the system contains the ability to autonomously navigate the pre-laid route indoors, or using a stereo image, to choose the route from point to point. The video odometer determines the direction and distance traveled by the image and constantly transmits this data to the central computer to correct the movement. When a GPS signal appears, the system automatically incorporates this data into location calculations platform and it calibrates the video navigation system based on exact RTK corrections.

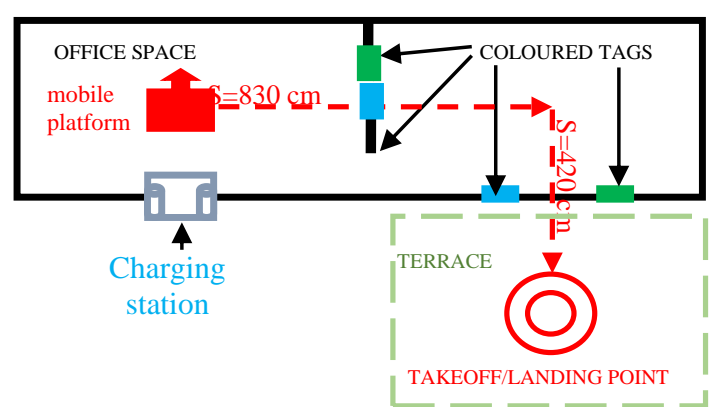

Figure 12. Mobile platform traffic scheme to take-off/landing point

\section{EXPERIMENT}

This complex was used to monitor the territory of $1 \mathrm{sq} \mathrm{km}$. (400 houses). For 4 weeks, the complex independently carried out aerial survey of the area, according to the images was built orthophoto mosaics, 3D models and controlled the dynamics of construction. Figures 13 and 14 show fragments of orthophotos on different dates.

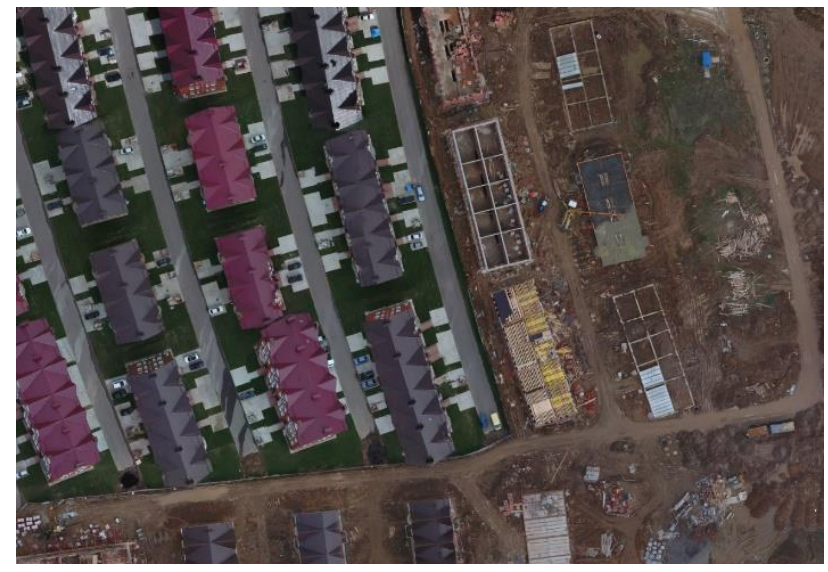

Figure 13. State of the site as of May 7, 2017

Every day 3 times a day, to fix the received building materials, the area was filmed. Every week, the photographs created an orthophoto and calculated the amount of work done. As a result, four 4 orthophotos of scale 1:500 were made, 93 video files, 776 images were created, 97 flights were made, 41 times the manipulator changed batteries in the UAV. He drove a total of $800 \mathrm{~m}$.

Experimental studies have shown that all the planned tasks, the complex has fulfilled completely. However, the experiment also showed that some nodes of the mobile platform, and navigation systems, in particular for faster UAVs, needed to be refined. This will reduce the time to measure the distance to the UAV and therefore faster to search, load the UAV and replace the battery. 


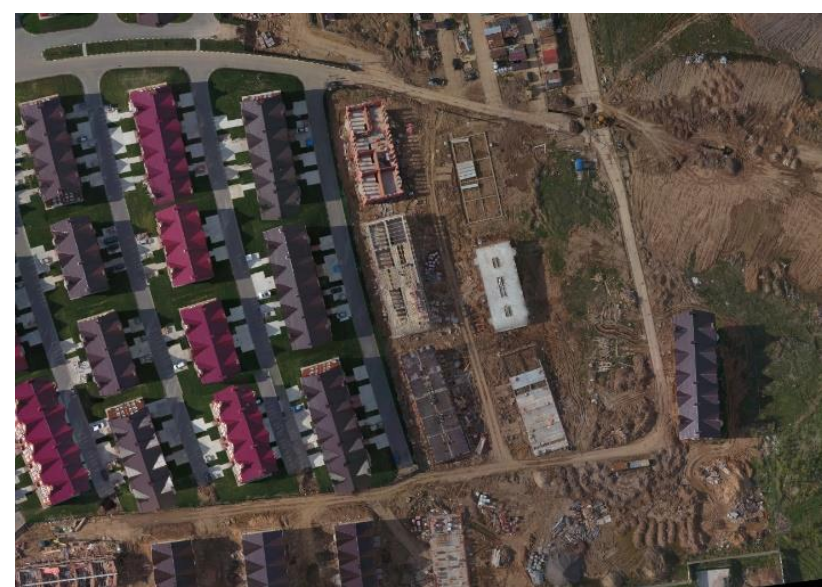

Figure 14. State of the site as of May 13, 2017

\section{CONCLUSIONS}

The paper describes the "Automated Information Generation System" (ASGI), which is designed to be carried out automatically by aerial survey of the object using an unmanned aerial vehicle and obtaining documents about the terrain (orthophoto, DTM, etc.). In the future, it is planned to refine the design for the use of UAVs with the multispectral sensors ParrotSequoia, RedEdge. This will expand the possibility of using the complex in the agricultural industry. On figure. 15 shows the first steps in this direction.

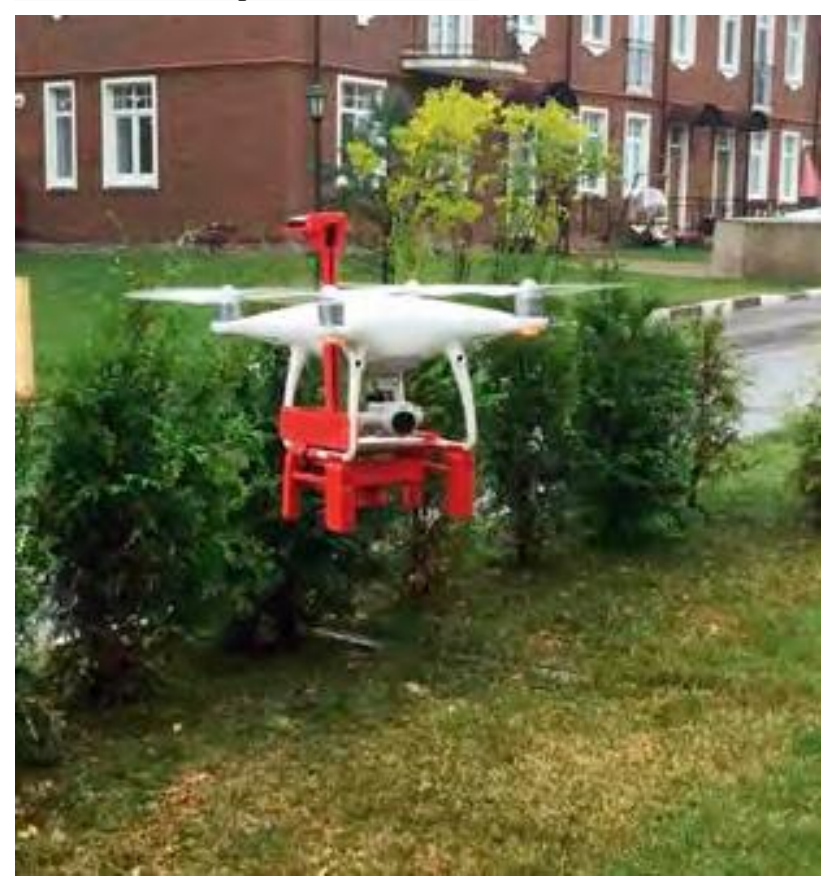

Figure 15. Special suspension for RedEdge multispectral sensor.

The complex will also be able to service UAVs with additional equipment. To work on the agricultural fields it is planned to develop a version of the mobile platform on a wheeled course with a radius of autonomy $20,000 \mathrm{~m}$., speed of $20 \mathrm{~km} / \mathrm{h}$. UAV lands on the ground. A hybrid complex (a robotic hangar with a mobile platform) is being created - take-off/landing from/on the box or land, the radius of autonomy $1000-20000 \mathrm{~m}$. We believe that the use of this technology to obtain information about the territory is the future of the industry.

\section{ACKNOWLEDGEMENTS}

The work was performed with the support by Grant 17-2904410 of Russian Foundation for Basic Research (RFBR).

\section{REFERENCES}

Badgers, A.P. 2010. Who's Who in Robotics. - M.: Book of Demand.

Bazhan, S. and Hosseininaveh, A. 2019. A moving obstacles planner algorithm for a six-wheeled surveying robot, Int. Arch. Photogramm. Remote Sens. Spatial Inf. Sci., XLII-4/W18, 191195, https://doi.org/10.5194/isprs-archives-XLII4-W18-1912019.

Borrmann, D., Heß, R., Houshiar, H. R., Eck, D., Schilling, K., and Nüchter, A. 2015. Robotic Mapping of cultural heritage sites, Int. Arch. Photogramm. Remote Sens. Spatial Inf. Sci., XL-5/W4, 9-16, https://doi.org/10.5194/isprsarchivesXL-5-W49-2015.

Calero, D., Fernandez, E., and Parés, M. E. 2017. Autonomous wheeled robot platform testbed for navigation and mapping using low-cost sensors, Int. Arch. Photogramm. Remote Sens. Spatial Inf. Sci., XLII2/W8, 67-74, https://doi.org/10.5194/isprs-archives-XLII-2-W8-67-2017.

Calisi, D., Cottefoglie, F., D'Agostini, L., Giannone, F., Nenci, F., Salonia, P., Zaratti, M., and Ziparo, V. A. 2017. Robotics and virtual reality for cultural heritage digitization and fruition, Int. Arch. Photogramm. Remote Sens. Spatial Inf. Sci., XLII5/W1, 503-508, https://doi.org/10.5194/isprs-archives-XLII-5W1-503-2017.

Chen, C., Zou, X., Tian, M., Li, J., Wu, W., Song, Y., Dai, W., and Yang, B. 2017. Low-cost multi-sensor robot laser scanning system and its accuracy investigation for indoor mapping application, Int. Arch. Photogramm. Remote Sens. Spatial Inf. Sci., XLII-2/W8, 83-85, https://doi.org/10.5194/isprs-archivesXLII-2-W8-83- 2017.

Chibunichev A.G., Makarov S.B., Poliakova E.V. 2019. Study of the possibility of using low-cost stereo cameras for robotic systems navigation. Izvestiya vusov «Geodeziya $i$ aerofotosyemka». Izvestia vuzov "Geodesy and Aerophotosurveying». 2019, 63 (6): 645-649. [In Russian]. DOI: 10.30533/0536-101X-2019-63-6-645-649.

Mustafa, K. A. A., Botteghi, N., Sirmacek, B., Poel, M., and Stramigioli, S. 2019. Towards continuous control for mobile robot navigation: a reinforcement learning and SLAM based approach, Int. Arch. Photogramm. Remote Sens. Spatial Inf. Sci., XLII-2/W13, 857-863, https://doi.org/10.5194/isprsarchives-XLII-2-W13-857-2019.

Kostrov, B.V. 2008. Artificial Intelligence and Robotics. - M.: Dialogue-Mifi.

Preco, M. 2007. 123 experiments on robotics. - M.: NT Press.

Wu, W., Chen, C., Cong, Y., Dong, Z., Li, J., Li, S., Dai, W., and Yang, B. 2019. Low-cost wheeled robot-borne laser scanning system for indoor and outdoor 3D mapping application, Int. Arch. Photogramm. Remote Sens. Spatial Inf. Sci., XLII-2/W13, 1155-1159, https://doi.org/10.5194/isprsarchives-XLII-2-W13-1155-2019. 